Ambiente \& Água - An Interdisciplinary Journal of Applied Science
ISSN 1980-993X - doi:10.4136/1980-993X
www.ambi-agua.net
E-mail: ambi-agua@agro.unitau.br

\title{
Estrutura da paisagem, relevo e hidrografia de uma microbacia como suporte a um programa de pagamento por serviços ambientais relacionados à água
}

\author{
doi: 10.4136/ambi-agua.1326
}

Received: 25 Feb. 2014; Accepted: 03 Jun 2014

\author{
Fernando Salles Rosa ${ }^{1}$; Kelly Cristina Tonello ${ }^{1^{*}}$; \\ Roberta de Oliveira Averna Valente ${ }^{1}$; Roberto Wagner Lourenço ${ }^{2}$ \\ ${ }^{1}$ Universidade Federal de São Carlos (UFSCAR), Sorocaba, SP, Brasil \\ Departamento de Ciências Ambientais \\ ${ }^{2}$ Universidade Estadual Paulista “Júlio de Mesquita Filho" (UNESP), Campus de Sorocaba, SP, Brasil \\ "Autor correspondente: e-mail: kellytonello@ufscar.br, \\ fesrosa@yahoo.com.br, roavalen@ufscar.br, robertow@sorocaba.unesp.br
}

\section{RESUMO}

O Pagamento por Serviços Ambientais (PSA) no Brasil está inserido na Política de Mudanças Climáticas e vem sendo executado para a proteção de recursos hídricos, biodiversidade, entre outros. O município de Ibiúna no Estado de São Paulo /SP apresenta aptidão para esse instrumento econômico, pois está localizado em posição estratégica ao abastecimento público, possui exploração agrícola e integra uma Unidade de Conservação na forma de Área de Proteção Ambiental - APA Itupararanga. Nesse contexto, a microbacia do ribeirão do Murundu, que está integralmente no município de Ibiúna/SP, foi selecionada para o desenvolvimento do projeto. O presente trabalho teve por objetivo a verificação em uma microbacia das interações entre a estrutura da paisagem, o relevo e a hidrografia por meio da classificação e tabulação cruzada entre os planos de informação de declividade e de cobertura e uso do solo, como subsídio à geração de um mapa temático de áreas prioritárias para conservação e preservação da água. As análises indicam que a microbacia apresenta predomínio de florestas em estágio médio/avançado (30,1\% da microbacia), concentrada na cabeceira e partes altas da bacia, bem como é crescente conforme aumento da declividade. Embora a microbacia apresente uma maior proporção preservada, foram observados diversos usos em áreas de preservação permanente. As ferramentas utilizadas demonstraram-se aplicáveis no suporte à tomada de decisão relacionada à definição de áreas prioritárias e no desenvolvimento de pesquisas e políticas públicas em PSA-água, com foco no incremento da governança dos recursos hídricos.

Palavras-chave: áreas prioritárias, impacto ambiental, conservação de solo.

\section{Landscape structure and slope of a watershed to support a program for payment for environmental services relating to water}

\section{ABSTRACT}

Payment for Environmental Services (PES) in Brazil is included in climate change policy and is being used to protect water resources, biodiversity, and other assets. The municipality 
of Ibiúna in São Paulo/SP is adequate for PES because it is located in a strategic position for public water supply and has agricultural production and an Environmental Protection Area - APA, Itupararanga. In this context, the watershed of the Murundu Stream, located entirely in the municipality of Ibiúna / SP, was selected for this work. This study involved the interactions between landscape structure, relief and hydrography in this watershed by the classification and cross tabulation of the slope and land use and land cover layers, as input for the generation of a thematic map of priority areas for conservation and preservation of water. The analyses indicate that most of the watershed is dominated by medium/advanced forests (30.1\% of the watershed extent) concentrated at the upper parts of the basin and increasing in area as the slope gets steeper. Although a large portion of the watershed is preserved, various uses were observed in areas of permanent preservation. The tools used in this study proved to be useful to supporting decision-making related to the definition of priorities of research and development of public policy in PES relating to water, with a focus on increasing water governance.

Keywords: priority areas, environmental impact, soil conservation.

\section{INTRODUÇÃO}

A água está entre os principais problemas que envolvem o meio ambiente. Este é um recurso natural renovável, mas que pode vir a se esgotar, caso seu uso seja mal manejado.

Estudos revelam que a manutenção da vegetação florestal permite a melhor retenção de água em bacias hidrográficas, reduzindo a ação erosiva no solo e alimentando os mananciais subterrâneos. Sua supressão pode, nas estações chuvosas, estar associada às inundações, aos deslizamentos e erosão do solo, e nos períodos de estiagem estar associada às secas severas. As leis ambientais surgiram visando um controle sobre tais situações, estabelecendo, por meio de normas e regras, uma ordem no uso dos recursos naturais, buscando-se assim, seu respectivo manejo sustentável.

Nos últimos anos, o conceito de Pagamento por Serviços Ambientais - PSA tem recebido considerável interesse como forma de incentivo à gestão sustentável de recursos naturais nas propriedades rurais. A ideia básica é que aqueles que "fornecem" serviços ambientais, por meio da conservação dos ecossistemas naturais, devam ser compensados pelos beneficiários do serviço, o princípio provedor-recebedor (WWF, 2006).

Um dos desafios para o planejamento e desenvolvimento de um programa para pagamento por serviços ambientais relacionados à água (PSA-Água) é estimar os benefícios das atividades de proteção dos recursos hídricos antes mesmo da implementação do projeto. Para tentar suprir esta necessidade fundamental no processo de convencimento de potenciais beneficiários e provedores, o uso de ferramentas de suporte à decisão é de grande relevância.

No âmbito de um projeto de PSA-Água, em um cenário mundial, adota-se a microbacia como área de abrangência. A Microbacia faz parte da estrutura primária da paisagem, ou seja, é a menor manifestação física que permite quantificar, de forma integrada, o funcionamento da natureza, possibilitando um enfoque sistêmico para as atividades florestais (Landell-Mills e Porras, 2002).

No Brasil, estima-se que o cultivo agrícola consuma cerca de $93,4 \%$ do total da água disponível (Setti et al., 2001), se tornando um dos grandes demandantes dos recursos hídricos. Antoniazzi (2008) destaca que apesar das atividades agrícolas gerarem impactos negativos no ambiente em geral, e nos recursos hídricos em particular, elas podem atuar também como conservadoras destes recursos. Isto acontece quando são adotadas técnicas compatíveis à preservação de recursos naturais, como a conservação do solo, o manejo integrado de pragas e doenças e à manutenção de vegetação natural nas zonas ripárias, entre outras. Ao utilizar 
sistemas de produção ambientalmente amigáveis, a agricultura pode produzir, além de alimentos, fibras e energia, adicionalidades aos serviços ambientais.

Em razão da significância da cobertura vegetal, a execução de Pagamentos por Serviços Ambientais - PSA para a manutenção da "floresta em pé" e até mesmo a criação de arranjos para a viabilização de Cotas de Reserva Ambiental- CRA previstas no Novo Código Florestal (Lei $\mathrm{n}^{\circ}$ 12.651/2012), demostram-se extremamente viáveis para a proteção dos recursos hídricos (Brasil, 2012).

Nesse contexto, no âmbito de um projeto de PSA-Água, pode-se transacionar sobre as práticas de conservação de remanescentes florestais, de restauração ecológica e florestal, de regeneração assistida e de conservação do solo para a amenização de processos erosivos em áreas prioritárias para a produção de água (Aronson et al., 2011; Veiga e May, 2010). Tais incentivos ambientais demonstram dinamismo e potencial como instrumentos econômicos de gestão voltados ao manejo integrado de microbacias hidrográficas.

Experiências piloto de PSA vêm sendo desenvolvidas em vários países, com abrangência e arranjos diversos. As discussões atuais em torno da estruturação de políticas nacionais justificam pesquisas voltadas ao equacionamento dos conflitos entre objetivos de eficiência e equidade na regulamentação do PSA.

A maior parte dos projetos de pagamentos por serviços ambientais no Brasil refere-se à conservação de água, iniciada com o pioneirismo em Extrema, sul de Minas Gerais em 2007. Essa foi a primeira iniciativa municipal brasileira que implanta o Pagamento por Serviços Ambientais baseada na relação existente entre a floresta e os serviços prestados por ela em relação à qualidade e quantidade de água a toda a sociedade. Além da iniciativa de Extrema, existem outros projetos como o de Joanópolis, Nazaré Paulista e Guaratinguetá no interior de São Paulo, o do rio Guandu, no interior do Rio de Janeiro.

O município de Ibiúna/SP possui sua economia baseada na agricultura e no turismo. Hoje com uma população de mais de 74 mil habitantes, é uma das 20 cidades de São Paulo que levam o título de "Estância Turística". Dos $1.093 \mathrm{~km}^{2}$ de Ibiúna, apenas de $10 \%$ é de zona urbana. Os outros $90 \%$ correspondem às áreas rurais de agricultura e pecuária de pequenos produtores e a áreas de preservação ambiental. Por essas características, Ibiúna foi selecionada pela Secretaria de Estado do Meio Ambiente como o único participante da Bacia Hidrográfica do Rio Sorocaba e Médio Tietê (UGRHI-10) para a implantação do projeto piloto de PSA-Água no Estado de São Paulo (Projeto Mina d'Água), sendo o projeto desenvolvido na microbacia do ribeirão do Murundu.

Dessa maneira, o objetivo desse trabalho consiste na verificação das interações entre o relevo, a hidrografia e a estrutura da paisagem, por meio da tabulação e classificação cruzada entre os planos de informação de declividade e de uso e cobertura do solo de uma microbacia, como subsídio à geração de um mapa temático de áreas prioritárias para conservação e preservação da água.

\section{MATERIAL E MÉTODOS}

\subsection{Caracterização da área/local}

A microbacia do Murundú possui 4.321 ha e está inserida na zona rural do município de Ibiúna-SP, entre as latitudes $267000 \mathrm{~m}$ e $277000 \mathrm{~m}$ E-W e longitudes $7363000 \mathrm{~m}$ e $7364000 \mathrm{~m}$ N-S. Sua rede hidrográfica está situada integralmente na sub-bacia do Alto-Sorocaba, e na porção sul da Área de Proteção/Preservação Ambiental - APA Itupararanga, onde se destacam os rios Sorocabuçu, Sorocamirim e Una. Estes rios são formadores do rio Sorocaba e do reservatório Itupararanga, responsável pela geração de hidroeletricidade e abastecimento de cerca de 1,5 milhões de pessoas em Sorocaba, Votorantim, Mairinque, Alumínio, Ibiúna e 
São Roque. Associada a densa rede hidrográfica e ao relevo montanhoso, a microbacia possui cerca de 250 nascentes e apresenta suscetibilidade alta a erosão (Marques e Kusano, 2009).

O clima para o município de Ibiúna, segundo a classificação de Koeppen, é o tropical de altitude (Cwa), com chuvas no verão e seca no inverno, com precipitações médias anuais em torno de $1.309 \mathrm{~mm}$ (CEPAGRI, 2012). A vegetação predominante é a Floresta Ombrófila Densa Montana.

\subsection{Planos de informação (P.I.s)}

O produto cartográfico digital foi obtido pela manipulação de cartas do Instituto Geográfico e Cartográfico de São Paulo - (IGC) no AutoCAD Land Development Desktop 2i. Foram digitalizados e os seguintes procedimentos/mapas temáticos: (1) Limite da área de estudo; (2) Rede hidrográfica; (3) Cabeceiras de drenagem (nascentes); (4) Declividade; (5) Mapa de uso e cobertura do solo.

O mapa de uso e cobertura do solo foi gerado pela análise de imagens orbitais digitais de sete bandas espectrais (1 a 7) do satélite Landsat-5, sensor TM, de órbita/ponto 219/077, obtidas em 24/08/2010, com resolução geométrica de 30 metros, exceto para a banda 6 , que é de 120 metros. As imagens possuíam $0 \%$ de nuvens e foram gratuitamente disponibilizadas pelo Instituto Nacional de Pesquisas Espaciais (INPE).

Todos os P.I.s foram padronizados para a resolução espacial igual a da imagem de satélite (1:30.000), no sistema de coordenadas Universal Transverso de Mercator (UTM) e Datum SAD69 Zona 22 Sul.

Nas operações de análise espacial e processamento digital de imagens foi empregado o software SIG-IDRISI 32 - Release 2. Para as verificações de campo, foi empregado um receptor GPS (Global Positioning System) de navegação Garmin eTrex Vista, de 12 canais e com antena interna, com exatidão nominal de $15 \mathrm{~m}$.

\subsection{Métodos}

\subsubsection{Mapeamentos e Planos de Informação}

O uso do solo diz respeito ao que o homem constrói ou insere sobre a superfície ou como maneja o solo, ao passo que a cobertura refere-se aos atributos físicos da superfície terrestre (McConnell e Moran, 2000).

O plano de informação de uso e cobertura do solo da microbacia do ribeirão Murundú foi obtido por meio do processamento digital das imagens orbitais, atendendo as seguintes etapas:

A) Pré-processamento das imagens: Previamente à classificação digital, foram reconhecidos visualmente na composição colorida os padrões de interpretação (cor, tonalidade, textura e forma) e os objetos homogêneos que poderiam pertencer a uma única classe, de acordo com os objetivos pretendidos. Foram realizadas as correções atmosféricas e geométricas. Para a correção atmosférica foi utilizado o Princípio da Reflectância Zero. Para tanto, avaliou-se os histogramas das imagens, identificando os pixels que deveriam apresentar valores de reflectância nula, os quais foram reclassificados para apresentarem valores digitais iguais à zero. Para correção geométrica foi utilizado o modelo de transformação polinomial de primeiro grau e o método de interpolação do vizinho mais próximo, tendo por base uma amostragem de pontos reais e as imagens digitais.

B) Definição das classes de uso e cobertura do solo: com auxílio de missões de campo e análise de imagens de satélite, e, principalmente, tendo em vista o mapeamento voltado à verificação das aptidões da microbacia para a implantação de um sistema de PSA-Água, a definição das classes de uso do solo e de cobertura vegetal para a área de estudo obedeceu à seguinte classificação:

- Agricultura: consiste predominantemente na olericultura, que corresponde ao cultivo de certas plantas de consistência herbácea, geralmente de ciclo curto e tratos culturais 
intensivos, como verduras e legumes. Nessa classe de uso do solo também foram incluídos os solos preparados para o plantio, assim como algumas áreas de fruticultura;

- Silvicultura: atividade econômica que está ligada diretamente com a exploração da madeira em monoculturas de uma espécie florestal (Teixeira, 2005).

- Campos rurais: identificados em propriedades rurais em que não há agricultura, mas houve intervenção antrópica, onde ocorre vegetação herbácea rala a herbácea arbustiva, homogênea ou heterogênea, geralmente em áreas não manejadas. Tal classe contempla também chácaras e sítios com presença de árvores isoladas, cercas-vivas e gramíneas, constituindo uma cobertura que pode ser quase contínua ou se apresentar sob a forma de tufos, deixando, nesse caso, alguns trechos de solo descoberto. Áreas de pastagem foram incluídas nesta classe;

- Instalações urbanas: presença de edificações agrupadas e parcelamentos do solo com ocupações residenciais (Teixeira, 2005);

- Vegetação de várzea (áreas alagadas): vegetação de composição variável que sofre influência dos rios, estando sujeita a inundações periódicas, ocorrendo desde áreas pantanosas até planícies alagáveis mais bem drenadas (IBGE, 2012);

- Mata ciliar: formação florestal edáfica conhecida existente às margens de rios, lagos, lagoas, córregos e nascentes, constituídas pelas mais variadas formações vegetais (Metzger, 2010; IBGE, 2012);

- Vegetação em estágio inicial: vegetação secundária que apresenta estrato herbáceoarbustivo a arbustivo, homogênea ou heterogênea, podendo ocorrer pequenas árvores (Brasil, 1994).

- Floresta em estágio médio e avançado: vegetação secundária arbóreo-arbustiva a arbórea densa, homogênea ou heterogênea, com presença de espécies emergentes e mata densa (Brasil, 1994).

C) Tomada das amostras de treinamento: foram tomadas com digitalização de polígonos em tela, sobre as áreas que representam as classes de uso e cobertura previamente determinadas. Foi estatisticamente definido o número de pixel amostrado por classe de uso e cobertura do solo, conforme proposto por Valente e Vettorazzi (2002).

D) Aplicação do algoritmo de classificação supervisionada: empregou-se o algoritmo de máxima verossimilhança (MAXVER) Swain e Davis (1978).

E) Verificação da exatidão de classificação: foi realizada por amostragem estratificada ao acaso e teve por base informações de campo e as próprias imagens de satélite. O número de amostras foi determinado como proposto por Eastman (1995) e empregado por Valente e Vettorazzi (2008), possibilitando a análise comparativa amostral entre a imagem e o campo (real). A partir disso, realizou-se o cálculo do índice Kappa $(\mathrm{K})$, o qual indica os pontos coincidentes entre as categorias definidas e a verdade terrestre, permitindo o cálculo do percentual de coincidência global e de cada classe.

F) Tratamento pós-classificação: foram feitas as alterações necessárias pós-verificação de campo e aplicado filtro de média $3 \times 3$, para atenuar presença de pixels isolados, comuns em produtos de classificação com o algoritmo MAXVER.

\subsubsection{Rede de drenagem}

O ordenamento dos canais de drenagem foi realizado conforme classificação de Strahler (1952).

\subsection{3. Áreas de Preservação Permanente (APPs) de recursos hídricos}

A caracterização e quantificação das APPs foi realizada para as nascentes, os cursos d'água, lagos e represas que compõem a rede hidrográfica da microbacia, conforme determinado pela Lei Federal $n^{\circ} 12.651 / 2012$. Foram consideradas as seguintes faixas: (a) de 
30 metros ao longo dos cursos d'água; (b) de 30 metros ao redor de lagos e reservatórios; e (c) de 50 metros ao redor das nascentes. Cabe salientar que os cursos d'água da microbacia do Murundú, possuem menos de 10 metros de largura.

\subsubsection{Declividade}

As faixas de declividade foram definidas a partir de critérios técnicos de fragilidade, formando uma categoria hierárquica de classes em graus de declividade, conforme estudos de capacidade de uso e de aptidão agrícola desenvolvidos por Ross (1994). Sendo assim, foram adotadas as seguintes faixas: até $6 \%$ grau de declividade (muito baixa); 6 a 12\% (fraca); 12 a 20\% (média); 20 a 30\% (forte); e acima de 30\% (muito forte). Foi realizada a tabulação cruzada entre uso e cobertura do solo e declividade, de forma a identificar a distribuição das classes de uso e cobertura para cada faixa de declividade.

\section{RESULTADOS}

A microbacia do Murundú apresentou o predomínio da classe cobertura do solo com vegetação natural (vegetação em estágio inicial, floresta em estágio médio/avançado, vegetação de várzea e mata ciliar), totalizando, juntamente com a rede hidrográfica $60,7 \%$ da área total (Tabela 1). As classes de usos do solo perfizeram o total de 39,3\% da microbacia.

Com relação às classes de cobertura do solo, a microbacia apresenta predomínio de florestas em estágio médio/avançado $(30,1 \%$ da microbacia), concentrada na cabeceira e partes altas da bacia. A mata ciliar $(8,4 \%$ da microbacia) ocorre nas margens dos corpos d'água, estando principalmente associada às microbacias de $4^{\mathrm{a}}$ ordem (Strahler, 1952) e suas respectivas confluências com o principal curso d'água da microbacia, o ribeirão do Murundu, conectando-se a um expressivo fragmento remanescente ao longo de seu trecho principal, se estendendo pela planície aluvial até o exutório da microbacia (Figura 1). Quanto aos canais de $1^{\circ}$ ordem, $41,2 \%$ das APPs possuem cobertura por floresta em estado avançado/médio e $29 \%$ de uso do solo distribuídos entre agricultura e campo rural.

A vegetação em estágio inicial (7,9\% da microbacia) ocorre de forma distribuída em toda extensão da microbacia, sendo composta por arbustos, herbáceas e espécies florestais iniciais de sucessão, como embaúba e angicos. A vegetação de várzea $(11,1 \%)$ apresenta expressividade de ocorrência, perfazendo estando principalmente associada à planície aluvial do ribeirão do Murundu apresentando-se geralmente contígua à mata ciliar.

Como relação às classe de uso do solo, a agricultura, na condição de uso do solo predominante, correspondeu a $20,4 \%$ da área total da microbacia. A agricultura praticada na região é, na sua grande maioria, irrigada através de sistemas por aspersão. Predomina a agricultura de base familiar, respondendo pela geração de renda da maior parte dos moradores, tais como, alface, couve, tomate, repolho, batata, brócolis, caqui, limão, morango, entre outros.

Os campos rurais $(13,8 \%$ da microbacia) ocorrem associados às estradas da microbacia $\mathrm{e}$ encontram-se distribuídos por toda a área. Estes campos rurais correspondem, principalmente, a proliferação de chácaras de lazer nas quais não houve significativa impermeabilização e/ou exposição do solo. Destaca-se sua ocorrência preferencial em localidades de maior altimetria, como ocorre com a floresta em estágio avançado/médio, nos topos arredondados do relevo e em áreas mais declivosas, diferentemente das áreas agrícolas, que ocupam preferencialmente na baixa microbacia, onde se encontram as áreas mais planas.

As estradas $(3,2 \%)$ por sua vez, ocupam área semelhante à hidrografia $(3,3 \%)$, as quais são utilizadas para viabilizar a mecanização, colheita e escoamento da produção. Nesse contexto, o eixo indutor de ocupação da microbacia é a Rodovia Municipal Tancredo de Almeida Neves (IBN-120), única via asfaltada, e que percorre o território de jusante à 
montante, ao longo das áreas mais planas, principalmente aquelas mais próximas ao ribeirão do Murundú.

As APP's totalizam 1014 ha, sendo que estas se encontram predominante protegidas por vegetação, atingindo, juntamente com a hidrografia, $76,5 \%$ da área total de preservação permanente. Por outro lado, $23,5 \%$ das APP's necessitam de incentivos à restauração (Tabela 1, Figura 2).

Tabela 1. Classes de cobertura e uso do solo e tabulação cruzada entre a declividade, o uso do solo e cobertura vegetal. Microbacia do ribeirão Murundú, Ibiúna,SP. 2013.

\begin{tabular}{|c|c|c|c|c|c|}
\hline & \multirow[t]{2}{*}{ Classes } & \multicolumn{2}{|c|}{ Área total da microbacia } & \multicolumn{2}{|c|}{ Dentro da APP } \\
\hline & & ha & $\%$ & ha & $\%$ \\
\hline \multirow{6}{*}{ 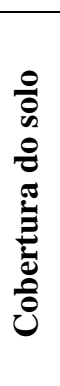 } & $\begin{array}{l}\text { Floresta em estágio } \\
\text { avançado/médio }\end{array}$ & 1299 & 30,1 & 307 & 30,2 \\
\hline & Mata ciliar & 364 & 8,4 & 117 & 11,6 \\
\hline & $\begin{array}{l}\text { Vegetação em estágio } \\
\text { inicial }\end{array}$ & 339 & 7,9 & 66 & 6,5 \\
\hline & Vegetação de várzea & 480 & 11,1 & 146 & 14,3 \\
\hline & Hidrografia & 140 & 3,3 & 140 & 13,8 \\
\hline & Sub total & 2622 & 60,7 & 776 & 76,5 \\
\hline \multirow{7}{*}{$\begin{array}{l}\stackrel{0}{0} \\
\dot{\infty} \\
\stackrel{0}{0} \\
\dot{0} \\
0\end{array}$} & Agricultura & 880 & 20,4 & 97 & 9,6 \\
\hline & Campo rural & 596 & 13,8 & 106 & 10,5 \\
\hline & Silvicultura & 50 & 1,2 & 4 & 0,4 \\
\hline & Instalações urbanas & 36 & 0,8 & 3 & 0,3 \\
\hline & Estradas & 137 & 3,2 & 28 & 2,8 \\
\hline & Sub total & 1699 & 39,3 & 238 & 23,5 \\
\hline & Total & 4322 & 100,0 & 1014 & 100,0 \\
\hline
\end{tabular}

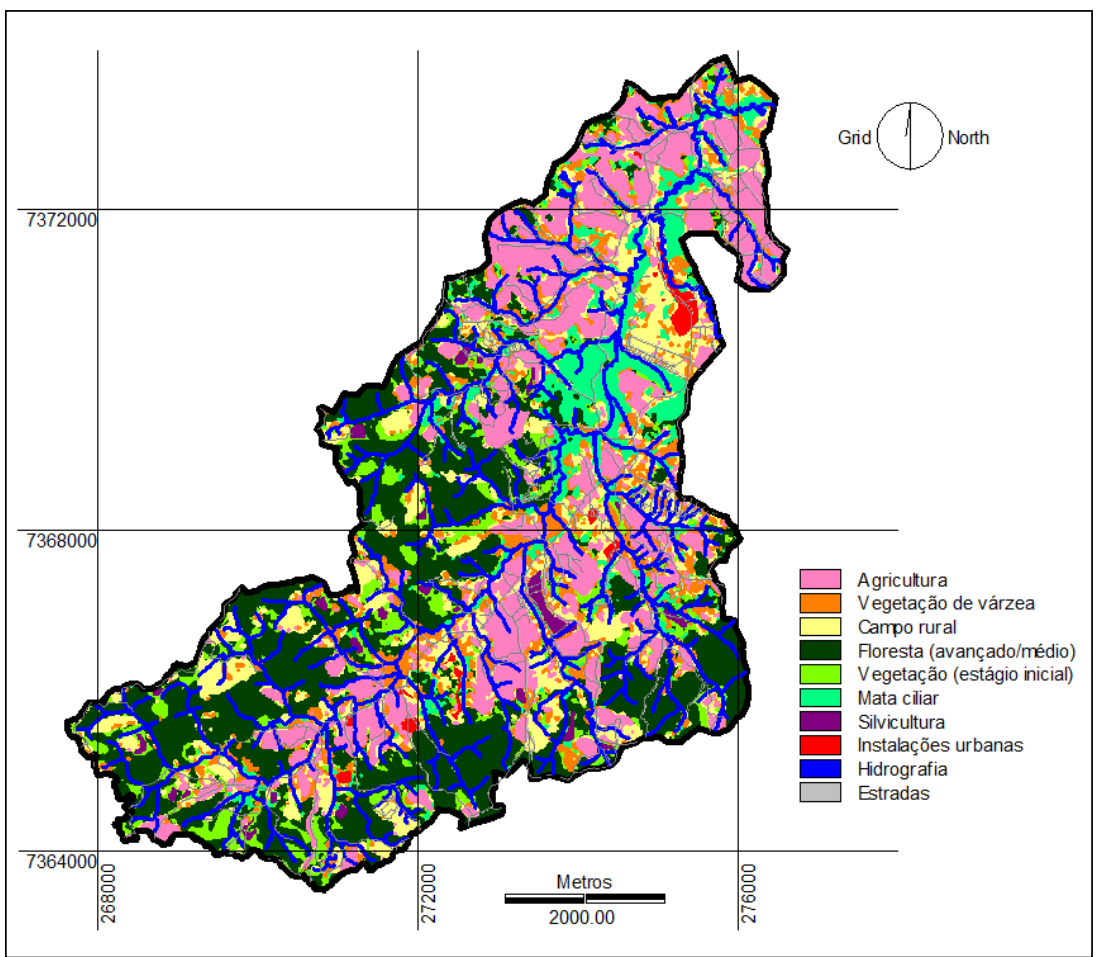

Figura 1. Uso e cobertura do solo na microbacia do Murundú, Ibiúna, SP, 2013. 
Destaca-se a presença significativa da cobertura florestal em estágio avançado/médio $(30,2 \%)$ devido à expressividade dos remanescentes na microbacia e da mata ciliar $(11,6 \%)$, a qual predomina no trecho de $5^{\mathrm{a}}$ ordem do ribeirão do Murundu, assim como da vegetação em estágio inicial (6,5\%). Por outro lado, a presença da vegetação de várzea $(14,3 \%)$, apesar de seus benefícios, indica também a ocorrência de intervenções sobre os corpos d'água, como barramentos, inclusive provocados pela passagem de estradas $(2,8 \%)$.

No caso dos usos do solo prevalecem a agricultura $(9,6 \%)$ e os campos rurais $(10,5 \%)$, indicando existir uma demanda ao atendimento da legislação ambiental como foco de um projeto de PSA-Água, cuja situação dessas APP's torna as propriedades não cumpridoras de sua função socioambiental na proteção dos recursos hídricos (NUSDEO, 2012). A silvicultura $(0,4 \%)$ e as instalações urbanas $(0,3 \%)$, ainda são pouco significativas e, portanto, demandam menos esforços para a restauração e/ou para compensação ambiental.

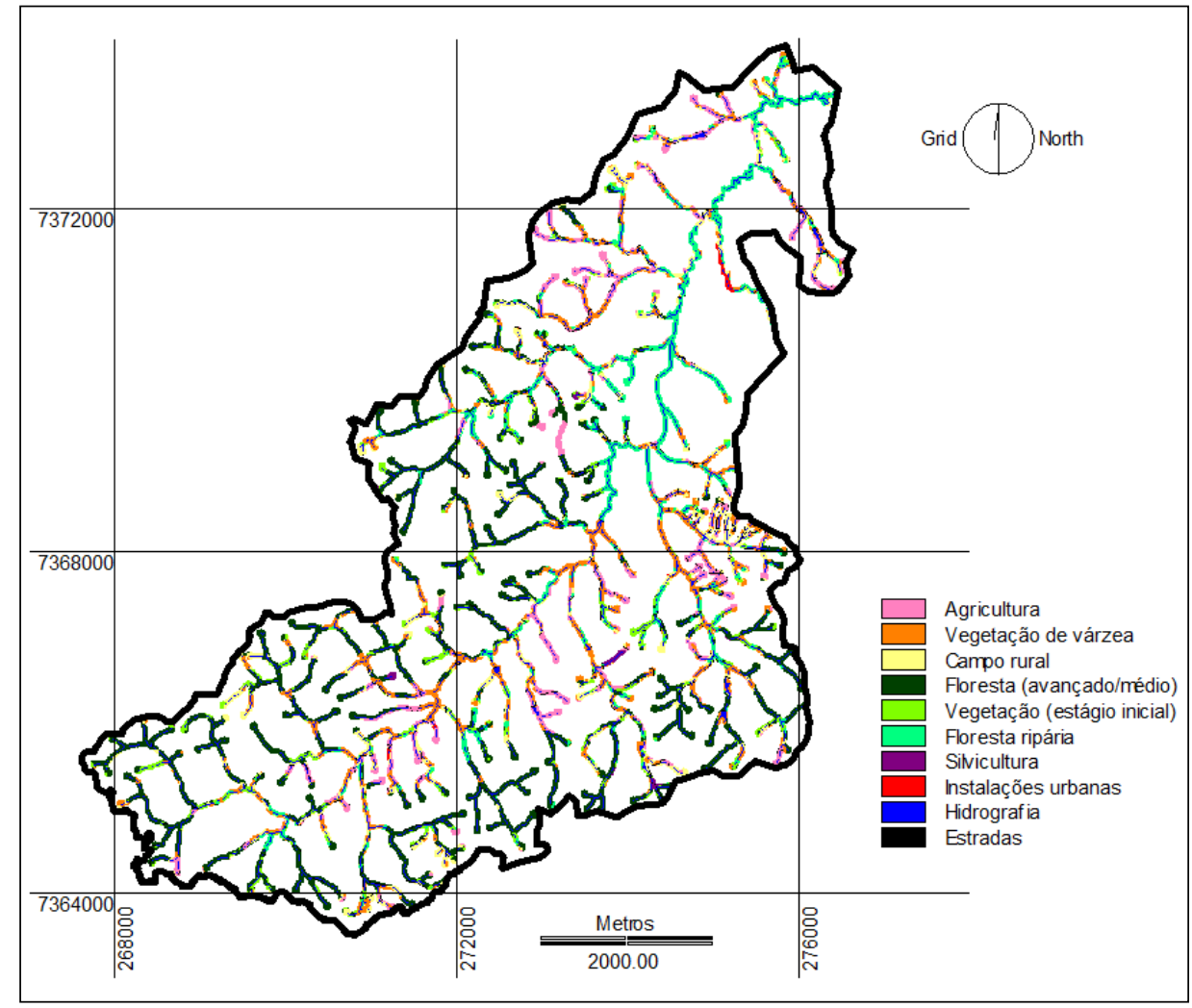

Figura 2. Uso e cobertura na Área de Preservação Permanente (APP) na microbacia do Murundú, Ibiúna, SP, 2013.

\subsection{Declividade $x$ cobertura e uso do solo}

A microbacia do ribeirão do Murundu apresentou 45,59\% de sua área com declividade "forte" e "muito forte". As categorias "muito fraca", fraca e média, corresponderam a 25,6\%, $10,20 \%$ e $18,61 \%$ da área em estudo, respectivamente (Figura 3) e a classificação cruzada (tabela 2) permitiu verificar a distribuição das áreas de cada categoria de cobertura e uso do solo em cada faixa de declividade.

$\mathrm{Na}$ categoria de cobertura do solo, a mata ciliar, vegetação várzea e hidrografia prevalecem nas faixas de declividade "muito baixa". Conforme o terreno aumenta a declividade, ocorre mudança com o aumento da cobertura florestal em estágio inicial e em estágio médio/avançado, onde essas duas classes possuem maior representatividade (129 e $607 \mathrm{ha})$ na faixa de declividade "muito forte". 
Tabela 2. Distribuição das classes de cobertura e uso do solo entre as faixas de declividade para a microbacia do ribeirão do Murundu, Ibiúna, SP, 2013.

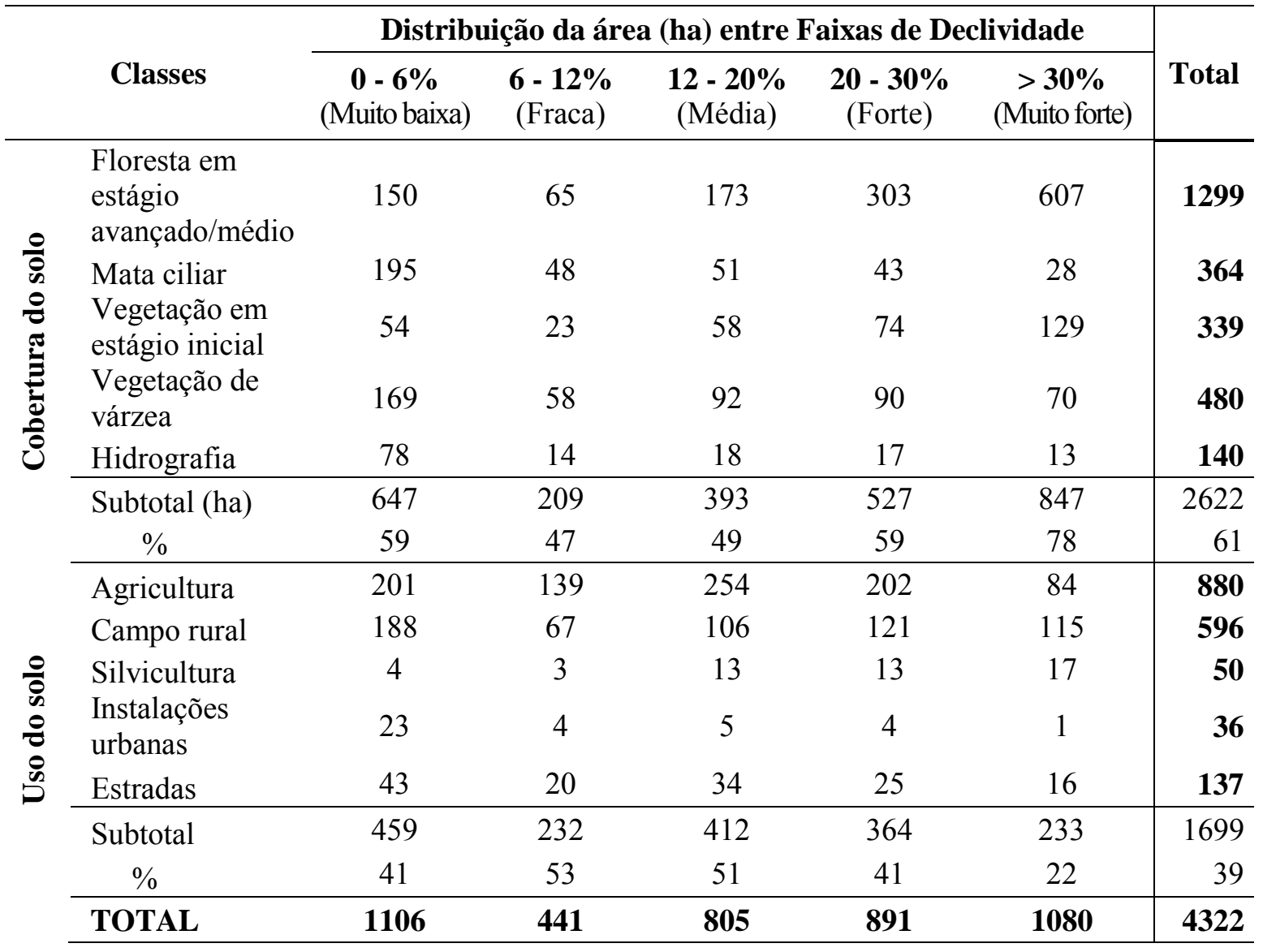

Na categoria de uso do solo predominam o campo rural, instalações urbanas e estradas nas faixas de declividade "muito baixa", a agricultura na "média", e, por fim, a silvicultura na "muito forte".

Por outro lado, a ocorrência significativa da cobertura vegetal $(58 \%)$ nas áreas mais planas está intimamente relacionada às matas ciliares (195 ha), confirmando a sua relação com as planícies de inundação como Áreas de Preservação Permanente. Nesse sentido, a vegetação de várzea também se destaca nas planícies de inundação (169 ha), geralmente contíguas às matas ciliares. Tal contexto enseja que a hidrografia predomine nas áreas planas, sobretudo devido a planície aluvial de ribeirão do Murundu.

No caso da vegetação em estágio inicial, a maior presença em áreas com declividades acentuadas (74 e 129 ha) também pode se relacionar com a dificuldade de manutenção de atividades agrícolas e consequente abandono das mesmas.

Assim, com relação à agricultura, nota-se a diminuição expressiva do uso nas declividades $>30 \%$ ( 84 ha). Já os campos rurais prevalecem como uso na faixa de declividade $>30 \%$ (115 ha), confirmando a possibilidade de intervenções, principalmente sobre a vegetação inicial. A introdução da silvicultura, já predomina nas faixas de declividade mais acentuadas (13 e 17 hectares). Confirma-se a predominância das instalações urbanas nas áreas mais planas (23 ha). Destaca-se a presença de ocupações, mesmo que pouco expressivas (1 ha), nas faixas de declividade $>30 \%$, supostamente em contrariedade com a Lei Federal $\mathrm{n}^{\circ}$ 6766/1979 (Brasil, 1979). 


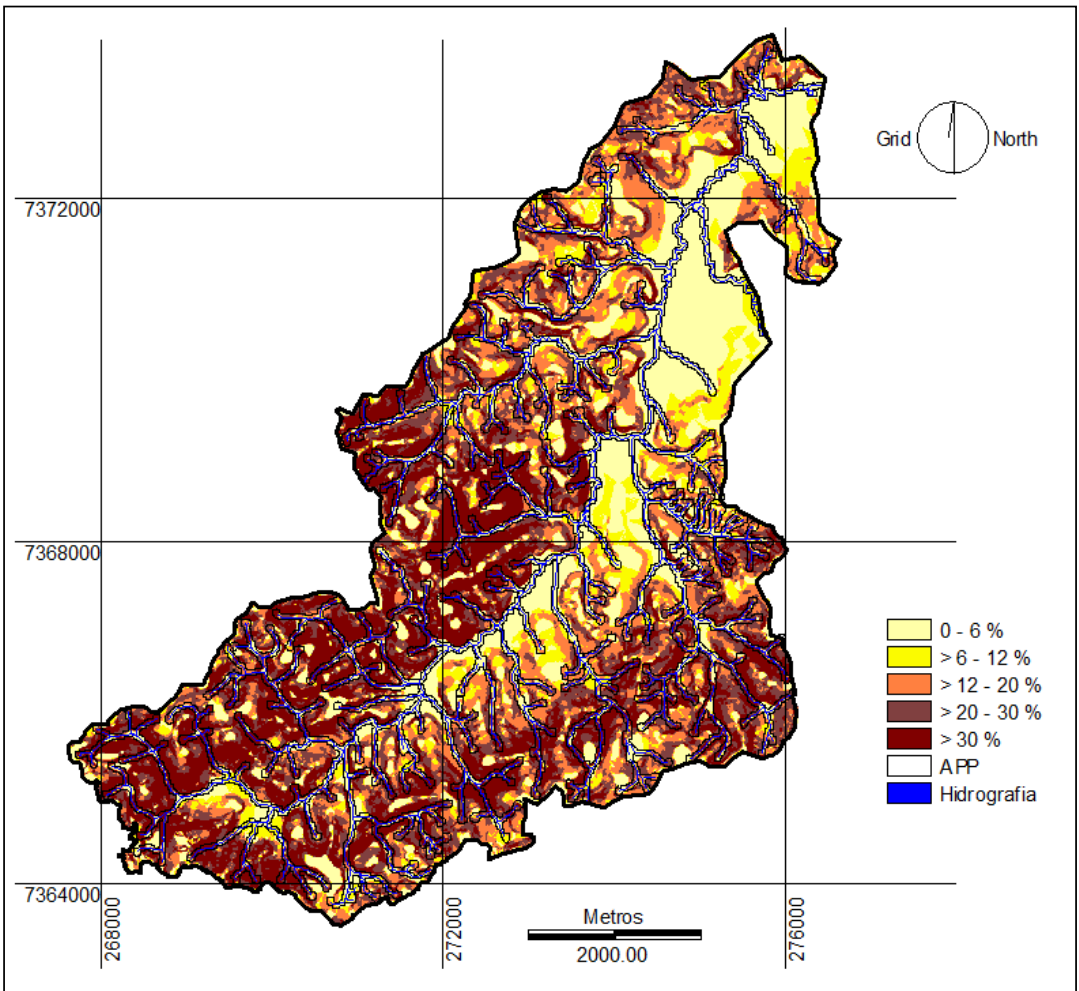

Figura 3. Faixas de declividade na microbacia do Murundú, Ibiúna, SP.

\section{DISCUSSÃO}

O levantamento realizado na microbacia do ribeirão do Murundu indica que $60,7 \%$ do território corresponde à cobertura florestal e os restantes 39,3\% se refere a usos diversos do solo. Tal condição possibilita que, no âmbito de um projeto de PSA-Água, sejam efetuados maiores pagamentos aos proprietários que detêm tais áreas protegidas em suas propriedades. Além disso, os esforços de restauração da vegetação seriam menores, possibilitando maiores investimentos nas práticas de conservação do solo.

A floresta em estágio avançado e médio representa a maior categoria de interesse na aplicação de um projeto de PSA-Água voltado à manutenção da "floresta em pé". Nota-se na microbacia do ribeirão do Murundu, que a maior presença de florestas está nas áreas mais declivosas ( $>20 \%$, Tabela 2$)$, ou seja, locais na paisagem mais susceptíveis ao escoamento superficial e por consequência, maiores perdas de solo e água. Tal condição reforça a dificuldade de intervenção e de estabelecimento de atividades antrópicas nessas áreas, inclusive atrelada à fiscalização e ao interesse na manutenção dos corpos d'água como fonte de irrigação agrícola e abastecimento de residências.

Por outro lado, são nessas regiões onde se concentra $30 \%$ das estradas da microbacia, que, se não forem adequadamente construídas, tornam-se indutoras de escoamento superficial e processos erosivos que podem interferir diretamente sobre os recursos hídricos.

Outro local de grande concentração de estradas $(31,0 \%)$ foi ao longo das áreas mais planas, principalmente aquelas mais próximas ao ribeirão do Murundu. Esse fato está associado à maior atividade agrícola nessa faixa de declividade criando demanda para a implantação de práticas ambientalmente adequadas, de modo a viabilizar a mecanização, colheita e escoamento da produção.

No caso da ocupação das áreas mais planas, os campos rurais estão estabelecidos no entorno das áreas de produção agrícola Isso indica a possibilidade de expansão de núcleos 
familiares ligados à produção rural, assim como o parcelamento do solo para fins urbanos, que também induz ao desmatamento.

Destaca-se a ocupação do bairro rural do Piaí, situado na planície de inundação da confluência do ribeirão do Murundu com o ribeirão Paiol Grande, o qual avança, inclusive, sobre as margens do afluente. Esta situação dificulta a proteção dos recursos hídricos com relação a demanda por saneamento básico, assim como favorece o risco de inundações. As novas e esparsas instalações urbanas apresentam-se como possibilidades de problemas socioambientais gerados pela interferência nos processos hidrológicos.

Grandes manchas de vegetação de várzea ocorrem em confluências dos corpos d'água da microbacia, inclusive nas travessias de estradas. Esta condição de várzea pode estar associada à remoção da mata ciliar e a consequente elevação do lençol freático, permitindo a introdução e adaptação das espécies vegetais características desses ambientes (Rocha, 2011).

No entorno imediato das matas ciliares, predomina os campos rurais em declividades mais acentuadas associados a instalações urbanas na planície, o que representa a pressão antrópica sobre tal remanescente, exaltando-o como prioridade em um projeto de PSA-Água.

As várzeas estão relacionadas aos pequenos banhados decorrentes de intervenções antrópicas na planície de inundação, como escavação de tanques para irrigação, lazer e estética. Nos trechos de cabeceira de drenagem a duração da inundação é muito pequena e também irregular para a demanda produtiva das áreas de produção agrícola. Contudo, apesar da ocorrência da vegetação de várzea, Metzger (2010) considera como serviço ambiental decorrente, juntamente com as matas ciliares, a fixação dos nitratos oriundos dos campos agrícolas.

A vegetação em estágio inicial observada na microbacia, geralmente está associada às bordaduras e às clareiras abandonadas no interior dos grandes fragmentos da cobertura florestal, com grande potencial para a regeneração assistida e ou enriquecimento vegetal em um projeto de PSA-Água. No entanto, verificou-se também que este tipo de cobertura nos pequenos fragmentos localizados em áreas de produção agrícola e em campos rurais. De acordo com Metzger et al. (2002) essa situação implica no maior isolamento e no aumento do efeito de borda, representando pressão sobre a regeneração da vegetação.

Estudos sobre a dinâmica da paisagem no Planalto de Ibiúna identificam a vegetação inicial como indicadora de áreas desmatadas e em regeneração, sobretudo em decorrência do abandono agrícola em áreas de maior declividade e próximas aos corpos d'água, inclusive para a manutenção da irrigação (Teixeira, 2005).

Diante do cenário apresentado e com base nos estudos desenvolvidos por Teixeira (2005), os quais consistiram na modelagem da dinâmica de uma paisagem do Planalto de Ibiúna nos anos de 1962, 1981 e 2000, pode-se inferir que haverá a redução expressiva da cobertura florestal e da vegetação inicial, haverá uma constância nas áreas de produção agrícola e haverá o aumento significativo dos campos rurais, das instalações urbanas e da silvicultura. Nesse sentido, a estratégica de proteção dos recursos hídricos da microbacia e a expressiva cobertura vegetal remanescente associada à pressão dos usos incidentes, evidenciam não somente a aptidão, mas a inclusão do território em mecanismos de conservação e de restauração ecológica.

Apesar da fragmentação da paisagem existente, estudos desenvolvidos por Bernacci et al. (2006) em fragmentos florestais remanescentes no município de Ibiúna demonstraram a ocorrência de espécies vegetais ameaçadas de extinção, pouco conhecidas ou mesmo inéditas para São Paulo. Esta condição ressalta a importância do PSA-Água não somente para a proteção dos recursos hídricos, mas também para a manutenção da biodiversidade regional.

Fundamental destacar os remanescentes de mata ciliar para a interceptação dos processos erosivos resultantes do escoamento superficial. Os remanescentes influem sobre a disponibilidade e a qualidade dos recursos hídricos, assim como sobre a conectividade 
hidrológica, que segundo Rocha (2011), representa o sistema rio-planície de inundação e as suas implicações para os padrões de biodiversidade.

Entre os diversos usos do solo, a predominância da agricultura (20,0\%) representa uma grande possibilidade à implantação do PSA-Água, uma vez que a conservação do solo e a consequente melhoria na produção poderiam garantir um maior envolvimento dos provedores e de suas respectivas propriedades, as quais potencialmente possuirão fragmentos de floresta e/ou vegetação inicial.

Sendo assim, entende-se que o fato de os remanescentes de vegetação estar sob o domínio privado e sujeitos a diferentes pressões (inclui-se os campos antrópicos e a iminente silvicultura), permitiria a combinação de serviços a serem remunerados (conservação, restauração e conservação do solo), possibilitando o incremento dos pagamentos, a maior atratividade ao provedor e, consequentemente, maiores efeitos sobre a proteção dos recursos hídricos. Diante dessa avaliação, a priorização de áreas surge como gargalo para diminuir os custos de transação e potencializar os efeitos de um projeto de PSA-Água.

\section{CONCLUSÃO}

A microbacia ribeirão do Murundu apresentou predomínio da floresta em estágio avançado e médio (30,05\% da microbacia), que se concentra na cabeceira e partes altas da bacia, bem como é crescente conforme o aumento da declividade e especialmente, ao redor dos recursos hídricos. Contudo, foram observados diversos usos de solo dentro das áreas de preservação permanente e em áreas de várzea, que podem estar afetando a produção de água da microbacia.

Nesse sentido, tendo em vista um programa de PSA-Água, é necessária a articulação entre os diversos atores responsáveis pela gestão dos recursos hídricos, assim como a ampliação e disseminação do conhecimento técnico e científico para promoção de práticas agrícolas sustentáveis relacionadas à conservação do solo e água vinculada com a produção agrícola.

O mapeamento em uma escala detalhada representa uma situação ideal e indispensável para o planejamento, desenvolvimento e monitoramento de ações no âmbito de um projeto de PSA-Água. As ferramentas utilizadas demonstraram-se aplicáveis no suporte à tomada de decisão relacionada à definição de áreas prioritárias e no desenvolvimento de pesquisas e políticas públicas em PSA-água, com foco no incremento da governança dos recursos hídricos.

\section{REFERÊNCIAS}

ANTONIAZZI, B. L. Agricultura como provedora de serviços ambientais para proteção de bacias hidrográficas. Revista Tecnologia \& Inovação Agropecuária, p. 52-63, junho 2008.

ARONSON, J. et al. What role should government regulation play in ecological restoration? Ongoing debate in São Paulo state, Brazil. Restoration Ecology, v. 19, n. 6, p. 690-695, 2011 .

BERNACCI, L. C. et al. O efeito da fragmentação florestal na composição e riqueza de árvores na região da Reserva do Morro Grande (Planalto de Ibiúna-SP). Revista do Instituto Florestal, v. 18, n. único, p 121-166, 2006.

BRASIL. Lei $n^{\circ} 6.766$ de 19 de dezembro de 1979. Dispõe sobre o parcelamento do solo e dá outras providências. Diário Oficial [da] República Federativa do Brasil. Brasília, 20 dez. 1979. 
BRASIL. Lei $n^{\circ} 12.651$, de 25 de maio de 2012. Dispõe sobre a proteção da vegetação nativa e dá outras providências. Diário Oficial [da] República Federativa do Brasil. Brasília, 28 maio 2012.

BRASIL. Conselho Nacional do Meio Ambiente - CONAMA. Resolução no 001, de 31 de janeiro de 1994. Estabelece as definições de vegetação primária e vegetação secundária nos estágios pioneiro, inicial, médio e avançado de regeneração da Mata Atlântica. Disponível em: <http://www.mma.gov.br/port/conama/res/res94/res0194.html>. Acesso em: 27 jun. 2013.

CENTRO DE PESQUISAS METEREOLÓGICAS E CLIMÁTICAS APLICADAS A AGRICULTURA - CEPAGRI. Clima dos municípios paulistas. Disponível em: $<$ http://www.cpa.unicamp.br/outras informacoes/clima_muni_228.html > Acesso em: 07 dez. 2012.

EASTMAN, J. R. Idrisi for Windows user's guide. Worcester: Clark University, 1995. $109 \mathrm{p}$.

GUEDES,F. B.; SEEHUSEN, S. E. Pagamentos por serviços ambientais na Mata Atlântica: lições aprendidas e desafios. Brasília: MMA, 2011. 272p.

INSTITUTO BRASILEIRO DE GEOGRAFIA E ESTATÍSTICA - IBGE. Manual técnico da vegetação brasileira. Rio de Janeiro, 2012. 271p. (Manuais Técnicos em Geociências, 1).

LANDELL-MILLS, N.; PORRAS, I. Silver bullet or fools_gold? A global review of markets for forest environmental services and their impact on the poor. London: IIED, 2002. 455p. (Instruments for sustainable private sector forestry).

MARQUES, V. K. G. P.; KUSANO, H. R. Estudo de caracterização morfométrica e análise de disponibilidade hídrica do Rio Murundu. 2009. 42f. Trabalho de Conclusão de Curso (Graduação em Engenharia Ambiental) - Universidade Estadual Paulista, Sorocaba, 2009.

MCCONNELL, W.; MORAN, E. (Eds.). Meeting in the middle: the challenge of meso-level integration. [S.1.]: LUCC, 2000. (LUCC Report Series, n. 4).

METZGER, J. P.; SIMONETTI, S.; UEZU, A.; DIEDERICHSEN, A.; GOULART, W. Conservação da biodiversidade em paisagens fragmentadas no Planalto Atlântico de São Paulo. São Paulo, 2002. Projeto FAPESP, Proc. 99/05123-4.

METZGER, J. P. O Código Florestal tem base científica? Natureza \& Conservação, v. 8, p. 92-99, 2010.

NUSDEO, A. M. Pagamento por serviços ambientais: sustentabilidade e disciplina jurídica. 1. ed. São Paulo: Atlas, 2012. Vol. 1. 179 p.

ROCHA, P. C. Sistemas rio-planície de inundação: geomorfologia e conectividade hidrodinâmica. Caderno Prudentino de Geografia, v. 1, p. 50-67, 2011.

ROSS, J. L. S. Análise empírica da fragilidade dos ambientes naturais e antropizados. Revista do Departamento de Geografia, v. 8, 1994. http://dx.doi.org/10.7154/RDG. 1994.0008.0006

SETTI, A. A.; WERNECK, J. E. F.; CHAVES, A. G. M.; PEREIRA, I. C. Introdução ao gerenciamento de recursos hídricos. 2. ed. Brasília: Agência Nacional de Energia Elétrica; Agência Nacional de Água, 2001. 328p. 
STRAHLER, A. N. Hypsometric (area-altitude) analysis and erosional topography. Geological Society of America Bulletin, v. 63, p. 1117-1142, 1952.

SWAIN, P. H.; DAVIS, S. M. (Eds.). Remote sensing: the quantitative approach. New York: McGraw-Hill, 1978. 396p.

TEIXEIRA, A. M. G. Modelagem da dinâmica de uma paisagem do Planalto de Ibiúna (1962-2000) e inferências sobre a sua estrutura futura (2019). $2005.118 f$. Dissertação (Mestrado em Ciências, na Área de Ecologia) - Universidade de São Paulo, São Paulo, 2005.

VALENTE, R. O. A.; VETTORAZZI, C. A. Análise da estrutura da paisagem na bacia do Rio Corumbataí, SP. Scientia Forestalis, v. 62, p. 114-129, 2002.

VALENTE, R. O. A; VETTORAZZI, C. A. Definition of priority areas for forest conservation through the Ordered Weighted Averaging method. Forest Ecology and Management, Amsterdam, v. 256, p. 1408-1417, 2008.

VEIGA, F. C. N.; MAY, P. H. Mercados para serviços ambientais. In: MAY, P. H. (Ed.) Economia do meio ambiente: teoria e prática. 2. ed. Rio de Janeiro: Elsevier, 2010.

WORLD WILDLIFE FUND - WWF. Payments for environmental services: an equitable approach for reducing poverty and conserving nature. [S.1.], 2006. 18p. 